\title{
Efeito da temperatura e da precipitação pluviométrica sobre a Composição Química do Leite Cru
}

\author{
Marinei Dolores Zorzella* \\ Graduanda do curso de Medicina Veterinária, DEAg, UNIJUÍ, 98700-000, Ijuí - RS \\ E-mail: marinei.zorzella@unijui.edu.br
}

Marnei Dalires Zorzella

Mestranda de Modelagem Matemática, UNIJUÍ, Ijuí - RS

\author{
Denize da Rosa Fraga José Antonio Gonzalez da Silva Sandra Fernandes \\ Departamento de Estudos Agrários - DEAg, UNIJUÍ, 98700-000, Ijuí - RS \\ E-mail: denise.fraga@unijui.edu.br
}

\begin{abstract}
$\underline{\text { RESUMO }}$
O leite dos bovinos é composto por vários nutrientes sintetizados na glândula mamária, dentre os quais, água, gordura, proteína, glicídios, uréia, minerais e vitaminas. Cada componente do leite tem uma proporção, que é influenciada pelo estado nutricional do animal, o qual é função da nutrição de cada vaca, sendo a composição nutricional das pastagens, base alimentar destes animais, diretamente influenciada pelo clima (temperatura e precipitação pluviométrica).

Na região noroeste do Rio Grande do Sul destaca-se o uso de gramíneas do gênero Cynodon, especialmente o Tifton 85. O gênero apresenta vantagens como elevada produtividade por área e qualidade, sendo altamente responsivo à adubação, apresentando resistência ao pisoteio animal, além de se adaptar a diferentes tipos de solo e condições climáticas [1]. O nitrogênio $(\mathrm{N})$ é o principal elemento nutricional que limita o desenvolvimento do Tifton $85 \mathrm{e}$ consequentemente tem maior impacto na produtividade da forragem [2]. Esse nutriente tem sua dinâmica diretamente afetada pela disponibilidade hídrica e temperatura.

Com intuito de verificar o efeito temperatura ambiente e do índice pluviométrico na qualidade do leite em rebanhos alimentados com Tifton 85 , fertilizado com $\mathrm{N}$, avaliou-se a composição do leite de vacas individualmente.

O presente trabalho foi realizado nos meses de fevereiro, abril e maio de 2013, no Instituto Regional de Desenvolvimento Rural da Universidade Regional do Noroeste do Estado do Rio Grande do Sul (IRDeR/UNIJUÍ), sob Latossolo Vermelho distroférrico típico [3]. A área experimental foi de 5,5 hectares, dividida em piquetes de pastagem de Tifton 85 , sob adubação de $400 \mathrm{Kg}$ de $\mathrm{N} \mathrm{ha}^{-1}$. Para o pastejo foram selecionadas 10 vacas da raça Jersey em início de lactação. As vacas eram ordenhadas duas vezes ao dia. Após a ordenha da manhã os animais eram suplementados com silagem e ração e após eram encaminhadas para a pastagem de Tifton 85 permanecendo por aproximadamente 4 horas e após, conduzidas à sombra. A segunda ordenha era feita a partir das 16 horas e após, os animais retornavam para pernoitar na pastagem de Tifton 85. O rebanho geral era constituído de animais de alta e baixa produção leiteira, mas para este experimento apenas as vacas de alta produtividade foram selecionadas.

O delineamento experimental adotado foi de blocos casualizados, em que cada bloco corresponde a um mês, com dez repetições representadas por dez animais Para a avaliação da qualidade do leite foi realizado um controle leiteiro por mês. Neste momento, foram coletadas amostras de leite de cada vaca, encaminhadas para análise em laboratório para quantificar o nível de nitrogênio ureico $(\mathrm{mg} / \mathrm{dL})$, gordura(\%) e proteína(\%).

A partir dos dados coletados foi realizada a análise de variância (Tabela 1), constatando que a temperatura nestes meses afetou significativamente, na probabilidade de $5 \%$ de erro, os nutrientes nitrogênio ureico e gordura, não tendo sido constatado efeito na proteína. Já o efeito da redução de precipitação pluvial não afetou negativamente a composição do leite, demonstrando que o Tifton 85 não perdeu qualidade nutricional em baixos índices pluviométricos. A temperatura média para os meses de fevereiro, abril e maio foram de 34,11 ;
\end{abstract}


32,05 e $28,25^{\circ} \mathrm{C}$, respectivamente e a precipitação pluviométrica acumulada dos meses de fevereiro, abril e maio de foi de 261, 57 e $68 \mathrm{~mm}$, respectivamente.

Tabela 1. Análise de variância da influência da temperatura e do nível de precipitação pluviométrica nos meses de fevereiro, abril e maio de 2013 na composição do leite de um rebanho Jersey, no Estado do Rio Grande do Sul, IRDeR/UNIJUÍ.

\begin{tabular}{lrccc}
\hline & GL & \multicolumn{3}{c}{ Quadro Médio } \\
\cline { 3 - 5 } Fonte de Variação & & URL $(\mathrm{mg} / \mathrm{dl})$ & GOR $(\%)$ & PRO $(\%)$ \\
\hline Meses quentes & 2 & $37.38^{*}$ & $2.49^{*}$ & $0.28^{\mathbf{N S}}$ \\
Erro & 27 & 4.58 & 0.63 & 0.10 \\
\hline Total & 29 & & & 3.67 \\
\hline Média Geral & & 14.65 & 21.69 & 8.65 \\
CV $(\%)$ & & 14.61 & \\
\hline
\end{tabular}

*Significativo em 5\% de probabilidade de erro, NS - Não significativo em 5\% de probabilidade de erro, GL - Grau de liberdade, URL - Nitrogênio Ureico, GOR - Gordura, PRO - Proteína, CV - Coeficiente de variação.

Na tabela 2, por meio do teste de Scott e Knott, constata-se que o teor de proteína do leite não sofreu interferência do ambiente (temperatura e precipitação pluviométrica), ao contrário dos demais nutrientes que foram afetados pelo clima. Os níveis de nitrogênio ureico mantiveram-se estáveis nos meses de fevereiro e abril, tendo um aumento significativo no mês de maio. A gordura por sua vez revelou um melhor desempenho no mês de maio.

Tabela 2. Análise de comparação das médias da composição do leite de um rebanho Jersey no Estado do Rio Grande do Sul, IRDeR/UNIJUÍ, através do Teste de Scott e Knott verificando o efeito da temperatura e precipitação pluviométrica nos meses de fevereiro, abril e maio de 2013.

\begin{tabular}{lccc}
\hline \multirow{2}{*}{ Tratamento } & \multicolumn{3}{c}{ Componentes químicos do leite } \\
\cline { 2 - 4 } & URL $(\mathrm{mg} / \mathrm{dl})$ & GOR $(\%)$ & PRO $(\%)$ \\
\hline Fevereiro/2013 & $14.71 \mathrm{a}$ & $3.20 \mathrm{~b}$ & $3.61 \mathrm{a}$ \\
Abril/2013 & $12.70 \mathrm{a}$ & $3.63 \mathrm{~b}$ & $3.51 \mathrm{a}$ \\
Maio/2013 & $16.56 \mathrm{~b}$ & $4.20 \mathrm{a}$ & $3.84 \mathrm{a}$ \\
\hline
\end{tabular}

URL - Nitrogênio Ureico, GOR - Gordura, PRO - Proteína.

Considerando a regressão linear múltipla, encontrou-se a equação que melhor representa cada nutriente descrito nestas condições, sendo: Nitrogênio ureico (URL) $=34.50+0.015 \mathrm{prec}$ 0.703 Tmax;Gordura $($ GOR $)=7.481-0.00099$ prec -0.1181 Tmax; Proteína $(\mathrm{PRO})=5.353+$ 0.00101 prec $-0.0587 \mathrm{Tmax}($ prec $=$ precipitação pluviométrica e Tmax $=$ Temperatura máxima $)$. O aumento do nível de nitrogênio ureico e gordura no leite está relacionado com a redução da temperatura e da precipitação pluviométrica no decorrer do período de fevereiro a maio de 2013.

Palavras-chave: Leite cru, Tifton 85, Regressão.

\section{Referências}

[1] VILELA, D. Potencial das pastagens de Cynodon na pecuária de leite. In: VILELA, D; RESENDE, J. C.; LIMA, J. (Ed) Cynodon forrageiras que estão revolucionando a pecuária brasileira. 1. ed. Juiz de Fora: Embrapa Gado de Leite, Brasil, 2005, p. 165-176.

[2] SARMENTO, P.; NASCIMENTO, R. C.; MARTINS, A. T.; CRUZ, M. C. P.; FERREIRA, M. E. Nutrientes limitantes ao desenvolvimento do capim tifton 85 em argissolo vermelhoamarelo. Boletim de Indústria Animal. V. 63, n. 1, p. 11-18, 2006

[3] EMBRAPA - EMPRESA BRASILEIRA DE PESQUISA AGROPECUÁRIA. Manual de métodos de análises de solo. Centro Nacional de Levantamento e Conservação do Solo. 